\title{
Assessment of health-promoting lifestyle in medical students of Rafsanjan University of Medical Sciences, Iran, in 2014
}

\author{
Esmaeili A, $\mathrm{PhD}^{1}$, Salem Z, MSc ${ }^{2 *}$, Sheikh Fathollahi M, $\mathrm{PhD}^{3}$, Rezaeian M, $\mathrm{PhD}^{4}$, Ebrahimi Nejad \\ $\mathrm{S}, \mathrm{MD}^{5}$ \\ 1-Associated Prof., Occupational Environment Research Center, Dept. of Social Medicine, Medicine Faculty, Rafsanjan \\ University of Medical Sciences, Rafsanjan, Iran. 2- Faculty Member, Dept. of Social Medicine and Occupational \\ Environment Research Center, Medical School, Rafsanjan University of Medical Sciences, Rafsanjan, Iran. 3- Assistant \\ Prof, Dept. of Epidemiology and Biostatistics, , Medical School, Rafsanjan University of Medical Sciences, Rafsanjan, Iran. \\ 4- Professor, Dept. of Epidemiology and Biostatistics, Occupational Environmental Research Center, Medical School, \\ Rafsanjan University of Medical Sciences, Rafsanjan, Iran.5-General Practitioner, Rafsanjan University of Medical \\ Sciences, Rafsanjan, Iran.
}

Received: December 2015, Accepted: February 2016

Background: Health-promoting lifestyle is one of the determination criteria for health factors and the prevention of health-threatening factors. According to the available statistics, 53\% of deaths are related to lifestyle. The aim of this study was to evaluate health-promoting lifestyles in medical students of Rafsanjan University of Medical Sciences (RUMS), Rafsanjan, Iran.

Materials and Methods: This was a descriptive study conducted in 2014 on 262 volunteer medical students. To collect data, a demographic information questionnaire and the Health-Promoting Lifestyle Profile II (HPLP-II) were used. Minimum and maximum scores of HPLP-II were 48 and 192, respectively. Data analysis was conducted using t-test, one-way ANOVA, Tukey's multiple comparison test, and non-parametric Kruskal-Wallis test.

Results: In this study, $58.8 \%$ of the participants were women. The mean age of the participants was $22.50 \pm 2.16$ years. The mean and standard deviation of the HPLP-II score of the medical students was $109.74 \pm 18.65$. There was a significant relationship between health-promoting lifestyle and variables of age $(\mathrm{P}=0.007)$, university entrance year $(\mathrm{P}<0.001)$, mother's education level $(\mathrm{P}=$ $0.003)$, and father's education level $(\mathrm{P}=0.011)$. However, no relationship was observed between health-promoting lifestyle and parental occupation and place of residence $(\mathrm{P}>0.050)$.

Conclusions: This study showed that the status of health-promoting lifestyles in medical students of RUMS was at a moderate level, but it is still at a great distance to the optimal level. Therefore, it is necessary to implement programs to promote a healthy lifestyle in order to maintain health in the youth until graduation.

Keywords: Student, Life Style, Health Promotion, Iran.

\section{Introduction}

Health is a complex and dynamic process that constantly changes throughout life (1). One of the main strategies for maintaining health is to have a healthy lifestyle. In other words, lifestyle is one of the most important factors affecting an individual's health and sickness (2). Lifestyle is the pattern of daily life, including nutrition type, dietary habits, relaxation and rest, smoking, physical activity, stress management, and use of health services (3). One of the most important objectives of promoting health is for individuals in a community to be able to control their health and increase their health level $(4,5)$. In fact, a healthy lifestyle is considered a valuable resource by which to reduce health problems, promote health, manage health, and improve lifestyle (1). Lifestyle plays an important role in the biological and psychological health of a society (6). The Health-Promoting Lifestyle Profile II (HPLP-II) is one of the criterions of

\footnotetext{
Corresponding author: Zinat Salem, Dept. of Social Medicine and Occupational Environment Research Center, Medical School, Rafsanjan University of Medical Sciences, Rafsanjan, Iran.

Email: salemzinat@yahoo.com
} 
health and prevention of health-threatening factors. The HPLP-II consists of the 6 dimensions of spiritual growth, health responsibility, nutrition, stress management, interpersonal relationships, and physical activity (7).

In the twenty-first century, the leading cause of morbidity and mortality in the world is still the non-communicable diseases such as cardiovascular problems, hypertension, cancer, and diabetes (1). The Health Promotion of life styles is the most important factor in the prevention of chronic diseases. According to statistics, $53 \%$ of deaths due to chronic diseases are related to lifestyle $(2,8)$.

Entering the university is one of the most important periods in the lives of young people and it is a bridge that connects the life of the youth to adulthood. In a study, unhealthy lifestyle among university students was reported (1). Researchers have reported that many students engage in risky behaviors such as smoking, drinking alcohol, physical inactivity, unhealthy diets, and poor sleep and rest. These high-risk behaviors will lead to poor health status among the youth and will continue into later stages of their lives (9). Studies have shown that living in dormitories, the specific living conditions, and obtaining relative independency will trigger high-risk behaviors that jeopardize the health of these young people (10). In a research conducted at Dezful University of Medical Sciences, Iran (11), the students' lifestyle was reported as poor, but in Kerman and Yazd Universities of Medical Sciences, Iran, the students had a good and suitable lifestyle $(12,13)$.

Due to the above facts, the increasing prevalence of chronic diseases associated with unhealthy lifestyle $(2,6)$, and the lack of studies on the lifestyles of students of Rafsanjan University of Medical Sciences, Iran, the aim of this study was to evaluate the health-promoting lifestyle among students of Rafsanjan University of Medical Sciences (RUMS) in the year 2014.

\section{Material and Methods}

This cross-sectional study was conducted in 2014 at RUMS. Census sampling was performed and all 350 medical students of Rafsanjan University of Medical Sciences were invited to participate in this study which was conducted under the supervision of the faculty members. Consequently, 262 students volunteered to participate in the study.

The inclusion criteria included being a medical student studying basic sciences and physiopathology, or internships and interns were studying. The exclusion criteria included the lack of willingness to participate in the study or suffering from a particular disease such as chronic diseases. A two-part questionnaire was used in this study. The first part contained demographic information including age, gender, and university entrance year, place of residence, education level, and parental occupation. The second part consisted of the HPLP-II questionnaire.

The HPLP-II questionnaire contains 48 questions, which assess health promoting behaviors in 6 dimensions including spiritual growth and self-actualization, responsibility towards health, interpersonal relationships, stress management, sport and physical activity, and nutrition. In this questionnaire, each question was scored on a 4-point Likert scale with the options of never (1 points), sometimes ( 2 points), often ( 3 points), and normally (4 points). The total score of health-promoting lifestyle was obtained by answering all 48 questions. The minimum and maximum scores of this questionnaire were 48 and 192, respectively. To evaluate the health promoting lifestyle in this study, a mean lifestyle score of less or equal to $49 \%$ of the total score was considered as poor status, $50 \%$ to $75 \%$ was considered as average status, and above $75 \%$ showed a good status among students (14). Higher scores indicated the superior lifestyle of the students. The reliability and validity of the questionnaire was evaluated by Mohammadi et al. at Ghazvin University of Medical Sciences, Iran. Cronbach's alpha for 
the whole questionnaire in this study was 0.82 and for the subcategories of nutrition, physical activity, responsibility for health, stress management, interpersonal relationships, and spiritual growth, it was $0.81,0.79,0.86,0.91$, 0.81 , and 0.79 , respectively (15). The HPLP-II and demographic questionnaires were distributed among the medical students by one of the researchers. After completion through self-report, the questionnaires were collected and the obtained data were entered into SPSS software (version 18, SPSS Inc., Chicago, IL, USA). In order to investigate the relationship between lifestyle and its dimensions, and the demographic variables, including age, gender, education, parental occupation, and university entrance year, independent two-sample t-test, one-way ANOVA, Tukey's multiple comparison test, and Kruskal-Wallis $\mathrm{H}$ test were used. The significance level was determined as 0.05 .

\section{Results}

Of the 262 students participating in the study, $154(58.8 \%)$ were girls, $164(62.6 \%)$ were residents of dormitories, and $113(43.1 \%)$ had entered the university during the years 20122014. In addition, $173(66 \%)$ participants were under 23 years of age. Their mean age was $22.50 \pm 2.16$ years. The education level of mothers of 110 participants $(42 \%)$ was diploma and fathers of 134 (51.1\%) students was higher than diploma. Moreover, mothers of $175(66.8 \%)$ students were housewives and fathers of $162(61.8 \%)$ of the students were employees.

The mean score of health-promoting lifestyles in students was $109.74 \pm 18.65$ (Table 1). In other words, in this study, the students obtained $56.83 \%$ of the total score of HPLP-II. This percentage reflected the lower-middle level of health-promoting lifestyles (50\% to $75 \%$ of the total score was considered as the average status) (14). Each dimension of health-promoting behaviors is shown in table 1. As shown, the highest score was related to health responsibility $(25.37 \pm 6.10)$. Sports and physical activity obtained the lowest score $(10.43 \pm 4.39)$.

Table 1: Descriptive indicators of the overall score and scores of the six dimensions of health-promoting lifestyle of the medical students in RUMS in $2014(n=262)$

\begin{tabular}{lccc}
\hline Health-promoting lifestyle and its dimensions & Minimum & Maximum & Mean \pm SD \\
\hline Health-promoting lifestyle & 61 & 176 & $109.74 \pm 18.65$ \\
\hline Spiritual growth and self-actualization & 10 & 36 & $23.29 \pm 4.60$ \\
\hline Responsibility for health & 13 & 45 & $25.37 \pm 6.10$ \\
\hline Interpersonal relationships & 14 & 36 & $23.92 \pm 4.25$ \\
\hline Stress management & 5 & 20 & $11.31 \pm 2.65$ \\
\hline Sport and physical activity & 6 & 24 & $10.43 \pm 4.39$ \\
\hline Nutrition & 7 & 28 & $15.43 \pm 4.83$ \\
\hline
\end{tabular}

Although in the present study the mean score of health-promoting lifestyle was higher in girls $(110.51 \pm 16.69)$ compared to boys (108.64 \pm 21.16$)$, this difference was not statistically significant $(\mathrm{P}=0.443)$. The overall mean score of lifestyle of dormitory residents was $110.41 \pm 18.68$, and it was higher compared to the students living in single homes (108.54 \pm 22.62$)$ and students living with their parents $(108.68 \pm 15.66)$. However, this difference was not statistically significant $(\mathrm{P}=0.780)$. Health-promoting lifestyle score did not show any statistically significant relationship with parental occupation ( $\mathrm{P}>$ 0.050 ). The lifestyle score is presented in terms of different variables in table 2. Tukey's multiple comparison test showed that the mean score of health-promoting lifestyles in the age group of 18-20 years was significantly higher than the other age groups $(\mathrm{P}<0.050)$. Moreover, the mean score of health-promoting lifestyles in students of the entrance years of 2012-2014 was significantly lower than other entrance years $(\mathrm{P}<0.05)$. The students whose 
mothers had a high school degree and lower had lower mean score of health-promoting lifestyle compared to students whose mothers had education degrees of higher than high school diploma $(\mathrm{P}=0.005)$. While, students whose fathers had a high school degree and lower had significantly lower mean score of health-promoting lifestyle compared to students whose fathers had education degrees of higher than diploma $(\mathrm{P}=0.034)$. There was no statistically significant difference between the other groups $(\mathrm{P}>0.050)$.

The mean score of responsibility in the age group of 18-20 years was significantly higher than the other age groups $(\mathrm{P}<0.050)$. The mean scores of stress management $(\mathrm{P}=0.005)$ and sports and physical activity $(\mathrm{P}=0.025)$ in the same age group (18-20 years) was significantly higher compared to the age group over 23 years. The mean score of the dimension of responsibility was significantly higher in women $(26.10 \pm 6.07)$ compared to men $(24.32 \pm 6.03)(\mathrm{P}=0.020)$. However, the mean score of sports and physical activity in men $(11.56 \pm 4.75)$ was significantly higher than women $(9.63 \pm 3.94)(\mathrm{P}=0.001)$.

Table 2: Comparison of health-promoting lifestyle scores based on the different demographic variables of the medical students in RUMS in $2014(n=262)$

\begin{tabular}{|c|c|c|c|c|}
\hline \multirow{2}{*}{\multicolumn{2}{|c|}{ Variables }} & \multicolumn{2}{|c|}{ Total score of health-promoting lifestyle } & \multirow{2}{*}{ P-Value } \\
\hline & & $\mathbf{N}(\%)$ & Mean \pm SD & \\
\hline \multirow{3}{*}{$\begin{array}{l}\text { Age groups } \\
\text { (years) }\end{array}$} & $18-20$ & $58(22.1)$ & $116.34 \pm 20.38$ & \multirow{3}{*}{0.007} \\
\hline & $21-23$ & $115(43.9)$ & $108.66 \pm 18.12$ & \\
\hline & $>23$ & $89(34.0)$ & $106.83 \pm 17.27$ & \\
\hline \multirow{3}{*}{$\begin{array}{l}\text { University } \\
\text { entrance year }\end{array}$} & $85-88$ & $69(26.3)$ & $105.68 \pm 17.03$ & \multirow{3}{*}{0.001} \\
\hline & $89-90$ & $80(30.5)$ & $106.16 \pm 18.03$ & \\
\hline & $91-93$ & $113(43.2)$ & $114.75 \pm 18.98$ & \\
\hline \multirow{3}{*}{$\begin{array}{c}\text { Mothers' } \\
\text { education level }\end{array}$} & High school and lower & $60(22.9)$ & $102.50 \pm 16.04$ & \multirow{3}{*}{0.003} \\
\hline & Diploma & $110(42.0)$ & $111.77 \pm 18.12$ & \\
\hline & Higher than diploma & $92(35.1)$ & $112.03 \pm 19.80$ & \\
\hline \multirow{3}{*}{$\begin{array}{c}\text { Fathers' } \\
\text { education level }\end{array}$} & High school and lower & $32(12.3)$ & $103.88 \pm 16.18$ & \multirow{3}{*}{0.011} \\
\hline & Diploma & $96(36.6)$ & $107.21 \pm 17.21$ & \\
\hline & Higher than diploma & $134(51.1)$ & $112.96 \pm 19.66$ & \\
\hline
\end{tabular}

One-way ANOVA, $\mathrm{P}<0.050$ was considered as statistically significant.

\section{Discussion}

The results of this study showed that from the total score of health-promoting lifestyle which was 192, the students participating in this study obtained a mean score of $109.74 \pm$ 18.65, which reflected the moderate lifestyle status of the students of RUMS. This result was consistent with the results of studies by Nilsaz et al. (11) and Tol et al. (16). The mean score of health-promoting lifestyle was higher in the age group of 18-20 years compared to the other age groups. This finding was consistent with that of the study by Tahmasbi (17). The study by Tahmasebi et al. showed that with the increase in age, the score of health-promoting lifestyle decreased. It seems that the youth place more importance on their lifestyle and as their age increases, they become more involved in other existing problems and their lifestyle becomes a subsequent priority (17).

The mean score of health-promoting lifestyles in the age group of 18-20 years in students of the entrance years of 2012-2014 was significantly higher than other entrance years. It seems that with the passing of university years, increasing study load, harder study courses, and the need to study more, most of the healthy habits of the students also change. Higher age groups, high volume of courses, and 24-hour shifts cause students to pay less attention to their lifestyle and develop unhealthy behavioral habits. Nola et al. 
reported that sixth year medical students had developed poor eating habits and an unhealthy lifestyle. Furthermore, with increase in education level, the number of meals and snacks reduced. Becoming busy, having to offer conferences, having different locations for each course, the need for timely relocation, and the need to spend more time on these activities are the main reasons for behavior changes and an unhealthy lifestyle (18). The mean score of health-promoting lifestyle did not have any significant relationship with the students' place of residency. The results of studies by Peker et al(19), Hong et al (20) and Kreutz et al(21) were consistent with that of the present study.

In this study, the mean score of healthpromoting lifestyle of the women was higher than men, but this difference was not statistically significant. Nevertheless, in the study by Farhadi, the quality of life (QOL) of women was significantly lower than that of the men (22). In the present study, the score of responsibility toward health was significantly higher in women compared to the men, which was consistent with the findings of Tol et al. (16). However, it was inconsistent with the findings of Motlagh et al. study. In the study by Motlagh et al., the score of responsibility was higher in men compared to the women (13). The differences between the findings of the present study and Motlagh et al. (13) were due to the differences in the study population. The study population in the present study consisted of medical students, while in the study by Motlagh et al. (13), the study population included medicine, dentistry, health, allied medical sciences, nursing, and midwifery students of Yazd University of Medical Sciences.

In addition, in the present study, the mean score of sports was significantly higher in men than women. Results of studies in Turkey and Hong Kong also showed that the highest scores of sports were related to boys compared to girls $(23,24)$. There findings were similar to that of the present study. In this study, the women obtained higher scores in interpersonal relationships than the men. This result was consistent with the results of studies conducted by Maheri et al (14), Tol et al. (16), and Lee and Loke (24). However, in the study by Alkandari et al. in Kuwait (25), boys received higher scores in terms of interpersonal relationships compared to girls. The difference in the results of this study and the mentioned study was due to the differences in the participants regarding their field of education. The participants of the present study were medical students, but the participants of the study by Alkandari et al. (25) consisted of nursing students. It seems that the longer duration of the medical course was the cause of the improved behavior in women compared to men.

In the present study, lifestyle had a significant relationship with parental education level; the closer parental education levels were to lower than diploma, the lower the overall score of students' health-promoting lifestyle. The same results were obtained by Babanejad et al. (26), Mansourian et al. (27) and Mazloomy Mahmoodabad et al (28).

The most important limitation of this study was the lack of interest and voluntary participation in the project by medical students. Thus, a considerable number of students did not enroll in the study due to these reasons. It is suggested that future studies be conducted on all academic disciplines of Rafsanjan University of Medical Sciences with a sufficient number of participants.

\section{Conclusion}

This study showed that the overall score of health-promoting lifestyle of the medical students of RUMS was lower-middle range. Given that the major burden of disease in developed countries is due to unhealthy lifestyles, it is necessary that measures be taken and programs be implemented to enhance the lifestyle of individuals in society, especially the youth groups and students of health sciences. 


\section{Acknowledgments}

Our sincere appreciation goes to the university research council for the research approval and financing, and all the students who participated in this study.

Conflict of interest: None declared.

\section{References}

1. Al-Khawaldeh OA. Health promoting lifestyles of Jordanian university students. International Journal of Advanced Nursing Studies 2014; 3(1):27-31.

2. Golmakani N, Naghibi F, Moharari F, Esmaily H. Health Promoting Life style and its Related Factors in Adolescent Girls. Journal of Midwifery and Reproductive Health 2013; 1(1):42-9.

3. Mohamadian H, Ghannaee M, Kortdzanganeh J, Meihan L. Reliability and construct validity of the Iranian version of health-promoting lifestyle profile in a female adolescent population. Int J Prev Med 2013; 4(1):42-9.

4. Enjezab B, Farajzadegan Z, Taleghani F, Aflatoonian A. Health promoting behaviors in a population-based sample of middle-aged women and its relevant factors in Yazd, Iran. Int J Prev Med 2012; 3(Suppl1):S191-S8.

5. Mirghafourvand $M$, Sehhati F, Rahimi $M$. Health-promoting lifestyle and its demographic predictors in infertile couples referred to infertility clinic of Tabriz Al-Zahra hospital, 2013. J Caring Sci 2014; 3(3):175-84.

6. Salmani Barough N, Nuktehdan $H$, Kazemnejad A, Nuruzi E. Comparing the lifestyles of first and final term female BS nursing students. Hayat 2003; 9(1-2):55-62.

7. Zohreh Kamrani Rad Z, Attarian F, Ebrahimipour H. Health-promoting lifestyle among Mashhad School of Health Students, Mashhad, Iran. Journal of Midwifery and Reproductive Health 2014; 2(3):195-203.

8. Steptoe A, Wardle J. Health behavior, risk awareness and emotional well-being in students from Eastern Europe and Western Europe. Soc Sci Med 2001; 53(12):1621-30.

9. Abolfotouh MA, Bassiouni FA, Mounir GM, Fayyad RCh. Health-related lifestyles and risk behaviors among students living in Alexandria University hostels. East Mediterr Health J 2007; 13(2):376-91.

10. Suraj S, Singh A. Study of sense of coherence health promoting behavior in north Indian students. Indian J Med Res 2011; 134(5):64552.
11. Nilsaz M, Tavassoli E, Mazaheri M, Sohrabi F, Khezli M, Ghazanfari Z, et al. Study of Healthpromoting behaviors and Life Style among students of Dezful universities. journal of ilam university of medical sciences 2012; 20(5):168-75.

12. Jalili Z, Nakhaee N, Haghdust A. Health promoting behavior and psychosocial health of Kerman university of medical science. Paper presented at: 3rd National Iranian Congress Health Education and Promotion. 2008 Oct 2830; Hamadan, Iran.

13. Motlagh Z, Mazloomy-Mahmoodabad SS, Momayyezi M. Study of Health-promotion behaviors among university of medical science students. ZJRMS 2011; 13(4):29-34.

14. Maheri B, Nabi Bahrami M, Sadeghi R. The situation of health-promoting lifestyle among the students living in dormitories of Tehran university of medical sciences, Iran. Journal of Health and Development 2013; 1(4):275-86.

15. Mohammadi Zeidi I, Pakpour Hajiagha A, Mohammadi Zeidi B. Reliability and validity of persian version of health promoting life style profile. Journal of Mazandaran University of Medical Sciences 2012; 22(Supple 1):103-13.

16. Tol A, Tavassoli E, Shariferad GhR, Shojaezadeh D. The relation between healthpromoting lifestyle and quality of life in undergraduate students at school of health, Isfahan university of medical sciences. Health System Research 2011; 7(4):1-7.

17. Tahmasbi A. Quality of life of women heads of households covered area well south of Tehran and its relationship with personal and familial. [MSc Thesis]. Tehran: University of Social Welfare and Rehabilitation Sciences; 2006.

18. Nola IA, Jelinić JD, Matanić D, PucarinCvetković J, Bergman Marković B, Senta A. Differences in eating and lifestyle habits between first and sixth year medical students from Zagreb. Coll Antropol 2010; 34(4):128994.

19. Peker K, Bermark G. Predictors of healthpromoting behaviors among freshman dental students at Istanbul university. International Dental Education 2011; 75(3):413-20.

20. Hong JF, Sermsri S, Keiwkarnka B. Healthpromoting lifestyle of nursing students in Mahidol university. Journal of Public Health and Development 2007; 5(1):27-40.

21. Kreutz G, Ginsborg J, Williamon A. Healthpromoting behaviours in conservatoire students. Psychol Music 2009; 37(1):47-60.

22. Farhadi A. The effect on the quality of life of rural education program of healthy lifestyle Dashti city. [MSc Thesis]. Tehran: University 
of Social Welfare and Rehabilitation Sciences; 2010.

23. Can G, Ozdilli K, Erol O, Unsar S, Tulek Z, Savaser $S$, et al. Comparison of the healthpromoting lifestyles of nursing and nonnursing students in Istanbul, Turkey. Nurs Health Sci 2008; 10(4):273-80.

24. Lee RL, Loke AJ. Health-promoting behaviors and psychosocial well-being of university students in Hong Kong. Public Health Nurs 2005; 22(3):209-20.

25. Al-Kandari F, Vidal VL, Thomas D. Healthpromoting lifestyle and body mass index among College of Nursing students in Kuwait: a correlational study. Nurs Health Sci 2008; 10(1):43-50.

26. Babanejad M, Khesht Zarin H, Sayehmiri K,
Delpishe A. Lifestyle investigation and its associated factors in students of Ilam University of Medical Sciences. Pejouhandeh Journal 2012; 17(5):252-7.

27. Mansorian M, Qorbani M, Solaimani MA, Maoodi R, Rahimi E, Asayesh H. A Survey of lifestyle and its influential factors among the university student in Gorgan. Journal of Jahrom University of Medical Sciences 2009; 7(1):62-71.

28. Mazloomy Mahmoodabad SS, Mehri A, Morowatisharifabad MA. The Relationship of health behavior with self-esteem and selfefficacy in students of Yazd Shahid Sadooghi University of Medical Sciences. Strides in Development of Medical Education 2007; 3(2):111-7. 